\title{
Building Bridges to Connect With Stakeholders: A Template for Success
}

\author{
Kimberly A. Reed \\ Past President, International Food Information Council Foundation, and Nominee, First Vice \\ President and Vice Chairman, Export-Import Bank of the United States \\ Washington, District of Columbia, USA
}

\begin{abstract}
The modern age of communication, with the 24x7 news cycle and "information overload," can impact our ability to connect with stakeholders. Kimberly Reed, a Washington professional who has built bridges for more than 20 years both across the aisle and around the globe with non-profits, trade associations, government officials, and risk and crisis communication professionals, presented a case study on Expo Milano 2015: "Feeding the Planet, Energy for Life" (the "World's Fair," which was the world's largest gathering and discussion on the topic of food). She shared best practices that featured Drs. Deanna and Tim Sellnow and provided practical resources to help communicators better connect with stakeholders and the media, bridge gaps, and deliver positive impact.
\end{abstract}

Keywords - Biotechnology; communication; Expo Milano; IDEA model; stakeholder

SUGGESTED CITATION: Reed, K. A. (2018). Building bridges to connect with stakeholders: A template for success. Proceedings of the International Crisis and Risk Communication Conference (pp. 1-4). Orlando, FL, USA. Nicholson School of Communication. https://doi.org/10.30658/icrcc.2018.1

\section{INTRODUCTION}

To more effectively prepare for and respond to real and perceived risk situations and crisis events, communication professionals should build bridges with stakeholders. During the opening plenary keynote, I shared strategies on how communicators from around the world could identify and get involved with important and relevant issues, especially where their expertise could make a positive difference for their communities, countries, and world. In order to show how such strategies have been put into action, I presented a case study on how the International Food Information Council (IFIC) Foundation built bridges and collaborated with diverse stakeholders from around the world - government; communication, agriculture, nutrition, health, and journalist professionals; civil society; nonprofits; academia; and the private sector - to address important communication topics relevant to the issue of feeding our growing planet, which will increase by two billion people by the year 2050 .

\section{METHODS}

Because of the expert/scientist and consumer/public disconnect on issues - where the expert "knows and thinks" and is fact-based and the public "feels and believes" and is value-based - communication professionals have the opportunity to bridge gaps to help with public understanding.

Communicators can take steps to determine where they can make a difference on issues to deliver positive impact. Useful tools include strategic planning processes, which outline vision, mission, goals, strategic objectives, and key implantation activities, and "SWOT" analyses, which identify strengths, weaknesses, opportunities, and threats. It also is a good practice to create a "Top Ten List" of issues on the horizon or "hotspots" and regularly update and refine it. Communicators, particularly those focused on crisis and risk, should stay informed of news on a daily basis and set up alerts for breaking issues, as the world now operates on a 24x7 communication news cycle.

As part of any planning process, it also is important to know the relevant short- and long-term issues that world leaders and decision-makers are considering. The United Nations General Assembly, World Health Assembly, G20, World Economic Forum, and other organizations regularly convene on pressing topics, make their agendas publically available, and often provide opportunities for civil society and others to participate. For example, governments, businesses, civil society organizations, and other stakeholders around the world currently are mobilizing efforts to achieve the United Nations' 17 Sustainable Development Goals (SDGs) by 2030. The SDGs, which include goals as diverse as zero hunger (Goal 2), good health and well-being (Goal 3), sustainable cities and communities (Goal 11), and responsible consumption and production (Goal 12), offer communicators a platform to which they can provide expertise in order to achieve greater success together. 
Finally, when it comes to effective communications, consumer attitudinal research is a key way to learn what consumers are thinking and what their real questions are. If you do not know what consumers are truly thinking, then a communicator could respond to unfounded misunderstandings or deliberate misinterpretations by a vocal minority, thereby amplifying those concerns and making a situation worse instead of better.

\section{RESULTS}

When it comes to big issues on the horizon, the world's population will increase from 7.2 billion to 9.6 billion between now and 2050. In order to meet this demand and help combat hunger, the United Nations estimates that the world will need 100 percent more food. Seventy percent of it must come from efficiency-enhancing technologies. The International Food Information Council (IFIC) Foundation, which has the mission of effectively communicating science-based information on health, nutrition, and food safety for the public good, identified this an important communication issue for it to address. Specifically, the Foundation would use its expertise to communicate the benefits of modern food production, including the role of biotechnology, as part of the solution to feeding the planet.

Over the past few years, the IFIC Foundation's Food and Health Survey, an annual consumer attitudinal survey that delves deeply into the issues of health and diet, food components, food productions, sustainability, and food safety, and its Consumer Perceptions of Food Technology Survey identified some key communication opportunities regarding the topic of feeding our world. For example, while seven in ten Americans see modern agriculture practices in having at least a small role in ensuring that all people have access to healthy food, a third need more information to make an informed decision about biotechnology (genetic engineering, which is used to produce crops and food products known as "GMOs"). While there is a diversity of opinions about the use of biotechnology to produce food products, twenty-five percent of Americans do not have enough information to form an opinion.

Building on this consumer attitudinal research, the IFIC Foundation was successful in securing over \$1 million in grant funding from the U.S. Department of Agriculture Foreign Agriculture Service, U.S. Department of State, and nonprofit foundations to develop two communicator guides (Food Biotechnology: A Communicator's Guide to Improving Public Understanding [1] and Food Safety: A Communicator's Guide to Improving Public Understanding [2]) and host numerous communication workshops in emerging market countries, including China, India, Indonesia, Vietnam, Egypt, Kenya, and Senegal. These workshops were done in collaboration and partnership with foreign government officials and agencies, communication experts, academicians, journalists, scientists, nonprofit foundations, and farmers. The in-country partners also identified and invited the workshop participants.

The workshops, which built bridges with thousands of participants from around the world, would feature noted experts as part of its agenda. For example, acclaimed crisis and risk communication experts Drs. Deanna and Tim Sellnow introduced their IDEA model (internalization, distribution, explanation, action) for effective instructional risk and crisis communication messages [3]. This model has demonstrated its utility across international borders and among disparate cultural groups [4]. Dr. Alan McHughen, Chair, Department of Botany and Plant Sciences, University of California, Riverside, presented on the science, regulatory structures, and role of biotechnology [5]. IFIC Foundation professionals David Schmidt, Andrew Benson, Anthony Flood, and Kimberly Reed introduced concepts including the importance of local consumer attitudinal research, how to work with the media, and highlights from the Food Biotechnology [1] and Food Safety [2] communicator guides and the Harvard School of Public Health-IFIC Foundation's Improving Public Understanding: Guidelines for Communicating Emerging Science on Nutrition, Food Safety and Health for Journalists, Scientist, and Other Communicators [6]. The in-country hosts, government officials, and experts provided local context, research, and culturally relevant communication tips, and, most importantly, facilitated earnest discussion. All of the pre- and post-workshop surveys showed that the workshops equipped participants with knowledge, improved understanding, and communication best practices.

In order to take the outcomes of these in-country workshops to the next level, the IFIC Foundation sought to convene a global summit with leaders from each of the participating countries, as well as from other strategic emerging markets. As the IFIC Foundation learned when it hosted a global summit on the topic of non-communicable disease [7] as side event to 2011 United Nations General Assembly, global convening events bring prominence and attention to an issue and build bridges for future success.

In surveying potential global convening events to which the IFIC Foundation could connect its global summit, Expo Milano (also known as the World's Fair), which would be held in Milan, Italy in 2015, was ideal. Expo Milano’s theme "Feeding the Planet: Energy for Life" - was central to the mission of the IFIC Foundation workshops in emerging market countries. With 147 official country participants, 20 million visitors, and 1 billion engaged virtual throughout the six months of Expo Milano, the IFIC Foundation identified this as the perfect platform. As such, on May 20, 2015, the IFIC Foundation hosted the EXPO 2015 Communications Summit: "Emerging Market Leaders Workshop on Effective Messaging on Global Food Production Issues.” Although the IFIC Foundation summit was not held on the grounds of Expo Milano [8] or in Milan, but, instead, at the U.S. Embassy in Rome, Italy, it was a strategic success. For example, by being based in Rome, the summit was proximate to one of the target audiences of invitees: emerging market country Permanent Representatives to the Food and Agriculture Organization of the United Nations (FAO). Its impact continues 
on through the participants who are now addressing major "feeding our world" issues in their home countries and on a global basis.

\section{DISCUSSION}

The IFIC Foundation's EXPO 2015 Communications Summit: “Emerging Market Leaders Workshop on Effective Messaging on Global Food Production Issues” allowed 60 diverse and influential emerging markets participants including those who had participated in IFIC Foundation workshops in their home countries, Permanent Representatives to FAO and Commissioners General to Expo - to meet each other and share expert insights and best practices. In addition, 165 stakeholders from around the world joined the conference via live stream video and over 800 viewers have watched the recorded summit proceedings on YouTube: https://youtu.be/_hKMGMFXHRs.

In addition to having the participants build bridges for future success, the summit built millions of bridges through social media. The summit generated 3 million social media impressions. An IFIC Foundation press release reached 60.5 million through traditional media. And, the IFIC Foundation's summit dedicated webpage www.foodinsight.org/globalsummit2015 - continues to serve as a valuable resource, receiving nearly 2000 visitors.

During the plenary session, Drs. Deanna and Tim Sellnow offered their insights as expert crisis and risk communication presenters at the various IFIC Foundation workshops in emerging market countries and the global summit. They underscored the value of collaboration. Following the global summit, the Sellnow's noted: "Feeding the burgeoning world population requires thoughtful, well-informed, and collaborative communication and policymaking. Moreover, doing so will require innovative food production processes based on accurate science and information. Thus, an intersection of science, traditional agriculture, and politics is at the heart of this essential planning and decision-making. Our hope is that the leaders charged with preparing to feed the world's growing population will base their decisions on open, honest, and accurate information. The world needs both the best science and the highest quality of risk communication to succeed in feeding more than 9 billion people by 2050.”

Additional partnerships and collaborations large and small also were essential in this success before, during, and after the summit, including with the U.S. and Italian governments, Diplomatic Courier [9], Economist Intelligence Unit, World Food Prize Foundation, Council for Agriculture Science and Technology, Cornell Alliance for Science, Global Farmer Network, Truth About Trade and Technology, Howard Buffett Foundation, James Beard Foundation, Abbott Foundation, National Foundation for Food and Agriculture Research, American University School of International Service's Conflict Cuisine Project, International Culinary Center, home organization of each participant, and others. Communicators should facilitate such collaborations at each and every opportunity, as they are essential for building bridges.

\section{CONCLUSION}

Building bridges is important concept for communication professionals to utilize to further their mission. The IFIC Foundation case study, culminating in its global summit, can serve as a universal "template" for any issue of importance.

As Mr. Ousseynou Kasse, Executive Director, National Biosafety Authority, Government of Senegal noted in his remarks at the summit (http://www.foodinsight.org/summer-2015-expo-milano - translated from French): "We learned much this morning, and I am sure that this information is going to be multiplied and shared around the world for the benefit of mankind. . . . S So it is that communication is at the very center of the ongoing debates. It is vitally important that this information is accessible to the public in countries around the world. The interaction by politicians and journalists is of fundamental importance to the communication process. It is so important to share this information with policy makers so that the people of the world can benefit. That is my key message from this workshop, and I would stress the importance of working together to spread the word[.]"

As the world prepares for next World's Fair is in 2020 in Dubai, UAE, communicators should take Mr. Kasse's message to heart. The theme will be "Connecting Minds, Creating the Future" and the subthemes include "opportunity," "mobility," and "sustainability.” For those communicators who contribute to this global discussion, your efforts will be for the benefit of mankind.

\section{Author Biography}

Kimberly A. Reed, J.D., West Virginia University College of Law, Nominee, Export-Import Bank of the United States, mreedkimberlyann@gmail.com. 


\section{REFERENCES}

[1] International Food Information Council Foundation. Food Biotechnology: A Communicator's Guide to Improving Public Understanding. 2013. Retrieved from http://www.foodinsight.org/education/foodbiotechnology-communicators-guide-improving-understanding

[2] International Food Information Council Foundation. Food Safety: A Communicator's Guide to Improving Public Understanding. 2015. Retrieved from http://www.foodinsight.org/food-safety-guide

[3] Sellnow, D. D., \& Sellnow, T. L. (in press). The IDEA model of effective instructional risk and crisis communication by emergency managers and other key spokespersons. Journal of Emergency Management.

[4] Sellnow, D. D., \& Sellnow, T. L. (2014). Instructional principles, risk communication. In T. L. Thompson (Ed.). Encyclopedia of Health Communication (pp. 1181-1182). Thousand Oaks, CA: Sage.

[5] Council for Agricultural Sciences and Technology (CAST) (2018). Regulatory Barriers to the Development of Innovative Agriculture Biotechnology by Small Businesses and Universities. Issue Paper 59. CAST, Ames, Iowa.

[6] International Food Information Council Foundation. Harvard School of Public Health-IFIC Foundation's Improving Public Understanding: Guidelines for Communicating Emerging Science on Nutrition, Food Safety and Health for Journalists, Scientist, and Other Communicators. $1998 . \quad$ Retrieved from https://www.foodinsight.org/Improving_Public_Understanding

[7] Fernstrom, M.H., Reed, K.A., Rahavi, E.B., \& Dooher, C.C. (2012). Communication strategies to help reduce the prevalence of non-communicable diseases: Proceedings from the inaugural IFIC Foundation Global Diet and Physical Activity Communications Summit. Nutrition Reviews. 70(5): 301-310. https://doi.org/10.1111/j.17534887.2012.00480.x

[8] Borron, A and Holt, J (2016). Expo Milano 2015: The Overview, Issue, and Future for Agriculture Communicators. Journal of Applied Communications: Vol. 100: Iss. 3. https://doi/10.4148/1051-0834.1225

[9] Schmidt, D.B., \& Reed, K.A. (2015, May). The Future of Food: Production, Innovation, and Technology. Diplomatic Courier: A Global Affairs Magazine. Vol. 9, Issue 3, pp. 10-14. 